\title{
Development of Tire-Wear Particle Emission Measurements for Passenger Vehicles
}

\author{
Yoshio Tonegawa $^{1} \cdot$ Sousuke Sasaki ${ }^{1}$
}

Received: 16 May 2019 / Revised: 4 December 2020 / Accepted: 9 December 2020 / Published online: 15 January 2021

(C) The Author(s) 2020

\begin{abstract}
In this study, we aimed to develop a new method for measuring tire-wear particles of less than $2.5 \mu \mathrm{m}$ generated from vehicle use. We also aimed to devise a method for evaluating the emission factor of tire-wear particles. To develop an evaluation method for tire-wear particles, we examined several factors, such as how tire components in airborne particles collected on a sampling filter were measured, the comparison of tire-wear particles obtained in a laboratory study and an on-road study, a method for measuring tire-wear particles using a test vehicle, and a method for evaluating tire-wear mass using a weighting balance. Measurements of tire-wear particles were carried out using the measurement method proposed herein. The amount of tire wear that the particles generated was almost constant in a vehicle speed range of $20-40 \mathrm{~km} / \mathrm{h}$ but was influenced by a change in lateral acceleration in the range of $0-0.4 \mathrm{G}$. Furthermore, the relationship between the emission of tire-wear particles and the lateral acceleration force can be shown by a quadratic polynomial. We estimated the emission factor of tire-wear particles by applying the relational equation to the speed profile of the JC08 used in Japanese exhaust gas tests. The emission factor of the test tire used in this study was $3.7 \mathrm{mg} / \mathrm{km}$-vehicle. The ratio of the tire-wear particles to tread wear mass was about $3.3 \%$ at $\mathrm{PM}_{2.5}$ and $3.7 \%$ at $\mathrm{PM}_{10}$.
\end{abstract}

Keywords Tire-wear particles $\cdot$ Measurement method $\cdot$ Determination of tire-wear particles $\cdot$ Tire tread wear mass

\section{Introduction}

Particulate matter (PM) of various sizes is suspended in the atmosphere. The environmental standard for $\mathrm{PM}_{2.5}$, which is defined as PM with a diameter of less than $2.5 \mu \mathrm{m}$, is set in each country to ensure atmospheric protection and mitigate harmful effects on health. As PM is generated by various processes and is released into the atmosphere, it is necessary to investigate the origin of the emissions to improve the air quality. The PM emitted from motor vehicles includes not only exhaust particles resulting from engine combustion but also non-exhaust particles such as tire and brake wear particles from vehicle use [1]. Recently, PM emissions from vehicle exhaust have decreased due to the strengthening of exhaust gas regulations and the development of new engine and after treatment technologies [2]. This has meant that, in terms of all particulate emissions from vehicles, the contribution of PM

Yoshio Tonegawa

ytone@jari.or.jp

1 Japan Automobile Research Institute, 2530 Karima, Tsukuba, Ibaraki 305-0822, Japan emissions from non-exhaust sources has become comparatively larger.

Test procedures for exhaust emissions from motor vehicles are widely applied worldwide for type approval. In these procedures, the emission factor of exhaust PM from one vehicle can be experimentally evaluated. However, evaluating the emission factor of non-exhaust particles from a vehicle is challenging because no test method has been determined.

A method for measuring non-exhaust particles for the evaluation of emissions is under consideration at the Particle Measurement Programme Informal Working Group (PMPIWG) of the United Nations Working Party for Pollution and Energy (GRPE) [3]. Methods for measuring brake wear particles have been summarized in prior literature $[4,5]$. It has been suggested that a common test procedure for measuring brake wear particles will be developed around the mid-end of 2019 [6]. However, the PMP-IWG has stated that it will "continue monitoring on-going projects and published data regarding the physical nature and size distribution of particle emissions from tire/road wear" for tire-wear particles [6].

The level of tire emissions present in the environment was investigated in the Tire Industry Project, a survey that focused on water bodies in Europe, Asia, and North America [7]. An average of $1000 \mathrm{ppm}$ tire emissions were found to be present 
in sediments in water bodies, while $0.08 \mu \mathrm{g} / \mathrm{m}^{3}$ in $\mathrm{PM}_{10}$ was found in the atmosphere and $1900 \mathrm{ppm}$ was found in soil. According to another report, the concentration of $\mathrm{PM}_{2.5}$ related to tire wear in the atmosphere was $0.03 \mu \mathrm{g} / \mathrm{m}^{3}$ on average, and the average contribution of total $\mathrm{PM}_{2.5}$ was $0.27 \%$ [8].

It is necessary to develop an emission inventory of tirewear particles to understand their impact on the environment and consider future measures. Therefore, a method for measuring tire-wear particles is required to accurately evaluate vehicle emissions. To study tire-wear particles in an indoor test, a road simulator consisting of four test tires and a circular pavement [9], and an inside drum test stand consisting of one test tire and a pavement on the inner drum [10,11], were utilized. In addition, research into non-tail pipe emissions on actual roads has been conducted using mobile sampling vehicles $[12,13]$. These studies mainly measured the particle size distribution and components of the particles generated during vehicle use.

To accurately evaluate the level of tire-wear particles generated in a laboratory or on a road, various factors involved in particle generation and evaluation must be considered. Tirewear particles are generated by the interaction between the tire and road surface, and the quantity generated varies according to the conditions of the road surface, such as the type of road and the amount of road dust present on the road surface. Particles generated by vehicle use can be collected through a filter method, which collects both re-suspended particles from the road surface as well as tire-wear particles. When seeking to analyze only the particles generated from tires, evaluating the level of tire-wear particles collected using a weight filter method is undesirable. Quantifying the specific components derived from tires on a collection filter by chemical analysis enables only tire-wear particles to be measured, excluding any particles from other origins.

In this study, we aimed to develop a new method for directly measuring tire-wear particles of less than $2.5 \mu \mathrm{m}$ released into the atmosphere by vehicles and establish a new method for evaluating the emission factor. We investigated the morphological observation of tire-wear particles obtained in both indoor and on-road tests, the effect of the vehicle speed and lateral acceleration on tire-wear particle generation, the contribution of tread mass to $\mathrm{PM}_{2.5}$, and the estimation of the emission factor of tire-wear particles in an actual driving pattern.

\section{Experimental}

\subsection{Test Tires}

Bridgestone 175/65R14 82S passenger radial tires were used in the investigation. The test tires were inflated with compressed air at $230 \mathrm{kPa}$. The load carrying capacity of these tires was $490 \mathrm{~kg}$. The vertical load of the test tire was $3.3 \mathrm{kN}$ and the target lateral forces were $0,0.3,0.6$, and $1.2 \mathrm{kN}$. The tire lateral acceleration was calculated by subtracting the lateral force with the vertical load and expressed as gravity acceleration $\mathrm{G}$.

\subsection{Quantification of Tire-Wear Particles on a Filter Sample}

Tire-wear particles generated by the friction between tires and a road are usually collected within a mixture of tire-wear particles, re-suspended particles, road wear particles, among others. Separation of the tire particles from the mixture is necessary to evaluate the emission of tire-wear particles from a vehicle. Typical tire treads are made from materials such as rubber/elastomer, carbon black, mixtures such as silica, and chemicals [14]. Although the blending ratios are different for every product, since rubber/elastomer is the most abundant component, the tire wear concentration in a mixture can be calculated by quantifying these components. However, as the amount of these components within a tire differs from one tire to another, it is necessary to analyze the ratio of the rubber/ elastomer component for each target tire.

In this study, we adopted a method of pyrolyzing the collected sample and quantifying the rubber component specific to the tire. In the tire analysis, Varian CP-3800 GC/1200 MS was used as an analyzer of the indicator substance obtained by performing thermal decomposition of the rubber components using T-DEX II manufactured by GL Science. Styrene produced by thermally decomposing the collected sample at $600{ }^{\circ} \mathrm{C}$ was used as an indicator substance and the relationship between the concentration of styrene as an index substance and the GC signal was evaluated [15]. The percentage of the indicator substance obtained, which was produced by pyrolysis of the tire tread, was also analyzed. The concentration of tire-wear particles contained in the collection filter was analyzed by the method discussed above.

\subsection{Evaluation Method of the Tire-Wear Mass by the Weighting of a Tire/Wheel Assembly}

The tire weight was measured to estimate the contribution ratio of tire-wear particles to $\mathrm{PM}_{2.5}$ to the tire wear mass. The weight of the tire and wheel assembly before and after the road test was measured in an air-conditioned room, and the tire-wear mass was calculated from the difference in the measured weight. The level of tire-wear mass in the test was considered to be low because the tire mileage for each test condition was as short as $17 \mathrm{~km}$ or less. In addition, we decided to measure the weight of each tire/wheel assembly because measurement errors would have arisen if the tire was scraped off due to removal from the wheel. Therefore, we used a balance 
that could measure the weight of a tire assembly of $13 \mathrm{~kg}$ and with changes of $0.1 \mathrm{~g}$ or less.

The tire weights were measured using a comparator balance KA50-2 manufactured by Metler Toledo. This balance had a maximum load of $52 \mathrm{~kg}$, a readability of $0.01 \mathrm{~g}$, and repeatability of $0.02-0.03 \mathrm{~g}$. Before weighing the tires, the dust on the tire surface was blown away using compressed air. The valve core was removed from the stem, and the tire was soaked overnight (over $8 \mathrm{~h}$ ) under air-conditioning to reduce the influence of pre-weighing conditions, such as the air pressure the inside tire and adsorption of moisture by the temperature.

\subsection{Experimental Setup of Indoor Test for Tire-Wear Particle Morphology}

To confirm the occurrence of tire-wear particles in an indoor test and on-road test, tire-wear particles were generated using an outer drum test stand attached to a pavement mimicking a real road on the surface of the outer drum. The mock-asphalt pavement was made by uniformly applying a mixture of stone, sand, and gravel with epoxy resin on the drum surface. Figure 1 shows a schematic of the outer drum test stand. The tire is driven around its horizontal axis at the highest point of the outer drum. This test apparatus can control the drum speed, wheel load, slip angle, and camber angle of the test tire. It is also possible to obtain the force exerted on the test tire during the running test by means of a three-component force sensor attached to the device. The tire-wear particles generated by friction between the test tire and drum surface were introduced into a constant volume sampler via a suction nozzle with a width of $220 \mathrm{~mm}$ and a height of $17.5 \mathrm{~mm}$ set behind the test tire. A mixing chamber with an inner diameter of $97.6 \mathrm{~mm}$ and a length of $880 \mathrm{~mm}$ was installed after the suction nozzle, and indoor air containing tire-wear particles was sucked at a flow rate of $5 \mathrm{~m}^{3} / \mathrm{min}$. Part of the mixed sample was isokinetically aspirated through a sampling tube with an inner diameter of $6 \mathrm{~mm}$ by a pump controlled at $20 \mathrm{~L} /$ min and collected in a sampling filter. The collection efficiency of the suction nozzle in this flow rate range was 0.98 to 1.0 in the experimental evaluation using gas.

\subsection{Method for Measuring Tire-Wear Particles Using a Road Tire Test Vehicle}

A wheel load was applied to the tire due to the weight of the vehicle, and the wheel force by the braking, driving, and turning behavior of the vehicle was transmitted to the tire. As a result, friction occurred between the tire and the road surface, and tire-wear particles were generated. Therefore, a test system that could control the tire behavior such as wheel load and force was required to stably generate tire-wear particles. Figure 2 shows a road tire test vehicle for measuring the tirewear particles emitted from a test tire. This test vehicle could change the factors (load, slip angle) that influenced the test tire's generation of tire-wear particles. Therefore, we installed a device for collecting tire-wear particles from this road tire test vehicle to evaluate the generated tire-wear particles.

The test tire and suction nozzle were attached to the road tire test car, and the generated tire abrasion dust was introduced from behind the test tire into the sampling device. The tire-wear particles were introduced into the mixing tunnel of the constant volume sampler at $5 \mathrm{~m}^{3} / \mathrm{min}$, and part of the mixed sample air was then isokinetically vacuumed by the pump via the filter folder. A multi cascade sampler was used as a PM sampler to divide the particle sizes into $\mathrm{PM}_{2.5}$ and $\mathrm{PM}_{10}$. A quartz filter of $47 \mathrm{~mm} \varphi$ and $47 \mathrm{~mm} \varphi \mathrm{OD} \times 20 \mathrm{~mm} \varphi$ ID were used as a collection filter for tire-wear particles. The test was conducted assuming that there was no particle loss in the sampling system.

Evaluation tests in this study were conducted on asphalt roads within a test course where the road surface condition was managed, as the level of generated tire-wear particles was thought to be different depending on the condition of the road surface. As a test road surface, we chose a straight road within the test course of the Japan Automobile Research Institute. Prior to the collection test of tire-wear particles, road debris (pebbles, tire treads) were removed with a road sweeper because differences in the road surface conditions could affect the generation of tire-wear particles. The collection test for the tire-wear particles was performed on a section of straight road of about $800 \mathrm{~m}$ on the test course. While applying a constant load and lateral force to the test tire, the test vehicle traveled on the straight

Fig. 1 Outer drum test stand and drum surface
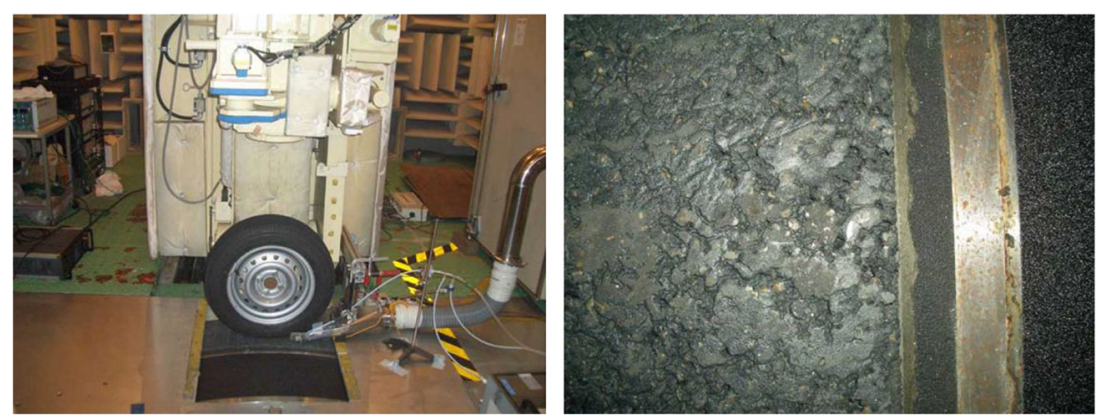


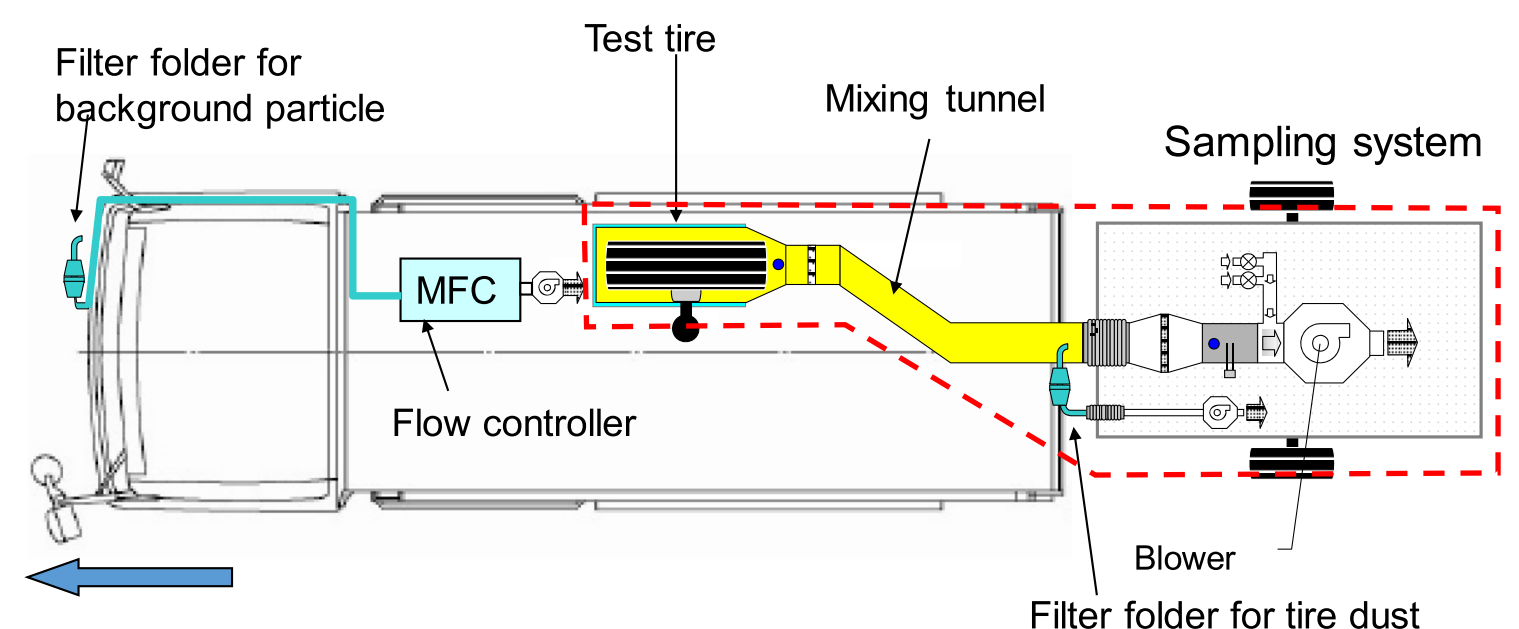

Fig. 2 Schematics of the test vehicle and sampling system for tire-wear particles

section of the course 10 times to collect an amount of tirewear particles that was sufficient for the analysis. The vehicle speed was controlled within the range of $20-40 \mathrm{~km} / \mathrm{h}$, and we set the maximum vehicle speed to $50 \mathrm{~km} / \mathrm{h}$ for safety reasons. The lateral acceleration was controlled in the range of $0-0.4 \mathrm{G}$ because the maximum acceleration/ deceleration in the test mode, matching actual driving according to regulations in each country, was $0.4 \mathrm{G}$ or less.

\section{Results and Discussion}

\subsection{Morphological Observation of the Tire-Wear Particles Obtained in Laboratory Tests and Road Tests}

The tire-wear particles were measured in laboratory tests. The number of tire-wear particles collected on the filter in the test showed little difference from the number collected in the laboratory room air. In addition, when the test was completed, tire dust, similar to dust from pencil erasers, adhered to the surface of the test tire, and tire dust of several $\mathrm{mm}$ in diameter was scattered around the test equipment. We thought that a phenomenon different than normal wear may have occurred in our laboratory tests. Therefore, the particles obtained in the laboratory test and road test were observed with an electron microscope to confirm the difference in particle morphology.

Morphological observation of the tire-wear particles on the collected sample was conducted using a scanning electron microscope. Figure 3 shows an electron micrograph of the tire-wear particles collected on filters in the laboratory test and road test. As shown in the figure, the tire-wear particles obtained in the laboratory test were elliptical spherical particles, and the particle diameter was about $400 \mu \mathrm{m}$ on the major axis. Contrastingly, the tire-wear particles obtained in the road test were spherical, and their diameter was approximately $10 \mu \mathrm{m}$. From the observation results of the generated particles, the morphology of the generated particles was different between the laboratory test and the road test. For these reasons, we concluded that it was better to evaluate the number of tire-wear particles in the road test than in the laboratory test.

\subsection{The Effect of Vehicle Speed and Lateral Acceleration on Tire-Wear Particle Generation}

An evaluation of the generation of tire-wear particles was conducted on the test course. To confirm the influence of the vehicle speed change, particle collection tests were conducted once each for vehicle speeds of 20,30, and $40 \mathrm{~km} / \mathrm{h}$ under a lateral acceleration of $0.2 \mathrm{G}$. In addition, to confirm the influence of the acceleration change, tests were performed once for each of the conditions with a lateral acceleration of $0,0.1$, and $0.2 \mathrm{G}$ under a vehicle speed of $40 \mathrm{~km} / \mathrm{h}$. As shown in Fig. 4, the emission of tire-wear particles was not affected by the change in speed. However, it was confirmed that emission of the tire-wear particles increased as the lateral acceleration increased. Since emission of the wear particles changed in accordance with the change in the lateral acceleration, the emission of tire-wear particles could be estimated by the acceleration applied to the tire.

We investigated the correlation between the lateral acceleration and the amount of tire-wear particles generated. Figure 5 shows the emission of tire-wear particle less than $2.5 \mu \mathrm{m}$ at each lateral acceleration obtained in road tests. The curve fit method with the quadratic polynomial regression was used to plot the graphs for the relationships between the tire-wear particle emissions and lateral acceleration. The coefficient of correlation between the amount of tire-wear particles and lateral acceleration was 0.6491. From this, there was a slight correlation between these relationships, though we predict that the correlation would be higher if the variation in the experiment was reduced. 


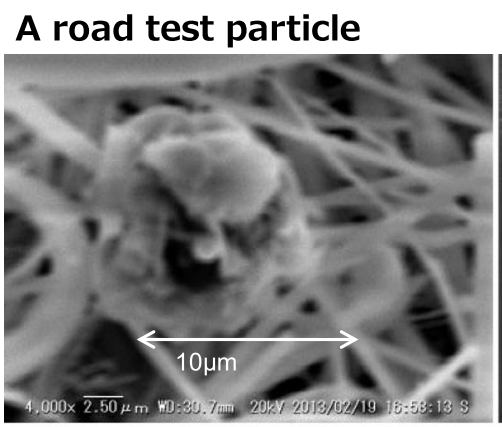

\section{A lab test particle}

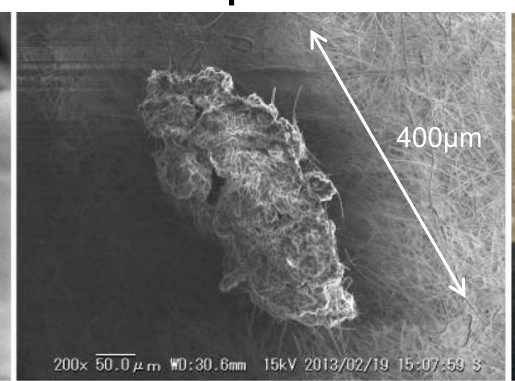

Tire surface after lab test

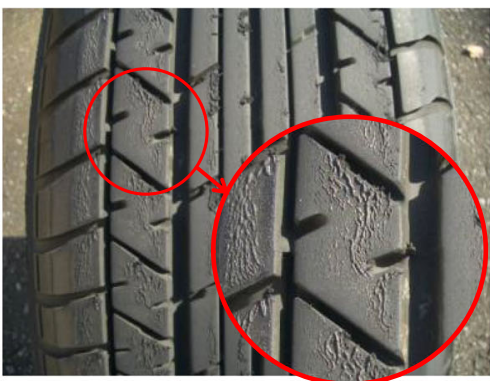

Fig. 3 Scanning electron microscope image of a road test particle and a laboratory test particle

\subsection{Estimation of the Emission Factor for Tire-Wear Particles}

We calculated the emission factor from the polynomial regression of the tire-wear particle emission and lateral force. The tire surface deformed when force was applied to the tire in both lateral and longitudinal acceleration. As a result, tire wear occurred due to slippage with the road surface. Depending on the tread pattern of the tire, the degree of tire wear could vary depending on the direction of acceleration applied to the tire. We estimated the emission factor of tire-wear particles, assuming that the number of tire-wear particles generated by change in acceleration was the same in both vertical and horizontal directions.

When the vehicle speed changed, the acceleration also changed. The tire-wear particle concentration $(\mathrm{mg} / \mathrm{km})$ calculated by the regression equation was generated instantaneously according to the change in acceleration. The total number of tire-wear particles in this concentration was multiplied by the instantaneous vehicle travel distance $(\mathrm{km})$. Therefore, the result of multiplying the tire-wear particle emission based on the acceleration and the integral value of the speed could be regarded as the total emission. The following formula was used to calculate the emission factor to apply the experimental results to actual driving patterns.

$\mathrm{EF}=\int \frac{v(t) \cdot f\left(a_{i}\right)}{d} d t$

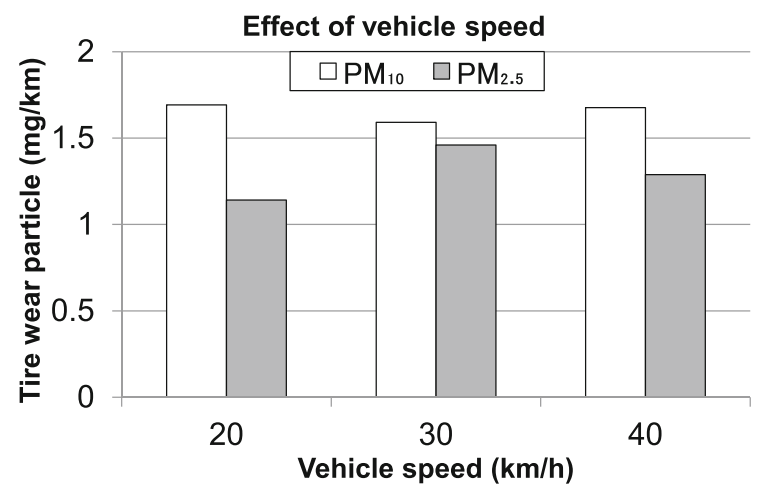

where $\mathrm{EF}$ is the emission factor of tire-wear particles $(\mathrm{mg} / \mathrm{km})$, $v(t)$ is the vehicle speed $(\mathrm{km} / \mathrm{h})$ at time $\mathrm{t}, f\left(a_{i}\right)$ is the tire-wear particle emission at each acceleration $(\mathrm{mg} / \mathrm{km})$ and $d$ is the distance vehicle driven during JC08 test cycle $(\mathrm{km})$.

Using the above formula, we estimated that the emission of tire-wear particles was less than $2.5 \mu \mathrm{m}$ in the driving cycle. The JC08 test cycle used in Japan's exhaust gas regulations was selected as the running pattern. The vehicle acceleration calculated from the time-speed data of JC08 was applied to the regression equation to calculate the instantaneous emission of tire-wear particles. Figure 6 shows the instantaneous and cumulative emission of tire-wear particles per one wheel determined by the calculation. The instantaneous emission of tirewear particles was high under high-speed acceleration and deceleration conditions, as well as when starting and braking the vehicle. As shown in the figure, the cumulative particle emission per wheel was $7.62 \mathrm{mg}$, and the distance in this mode was $8.17 \mathrm{~km}$. Therefore, the tire emission factor of one tire in this running pattern was $0.932 \mathrm{mg} / \mathrm{km}$-tire. We assumed that the four tires of a passenger car would be worn in the same way and estimated that the emission factor of tire-wear particles less than $2.5 \mu \mathrm{m}$ was $3.73 \mathrm{mg} / \mathrm{km}$-vehicle.

\subsection{Contribution of Tire-Wear Particles Less than $2.5 \mu \mathrm{m}$ to Tread Wear Mass}

We investigated how much of the worn tire tread was discharged as particles below 10 and $2.5 \mu \mathrm{m}$ by measuring

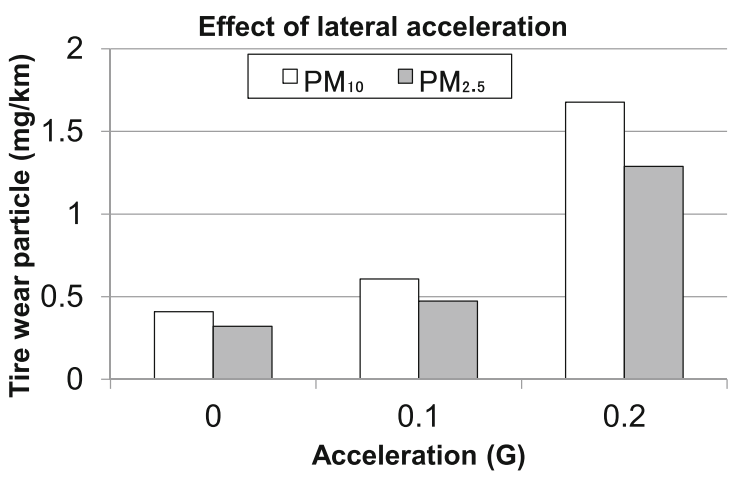

Fig. 4 Effect of vehicle speed and lateral acceleration of the tire on tire-wear particle generation 


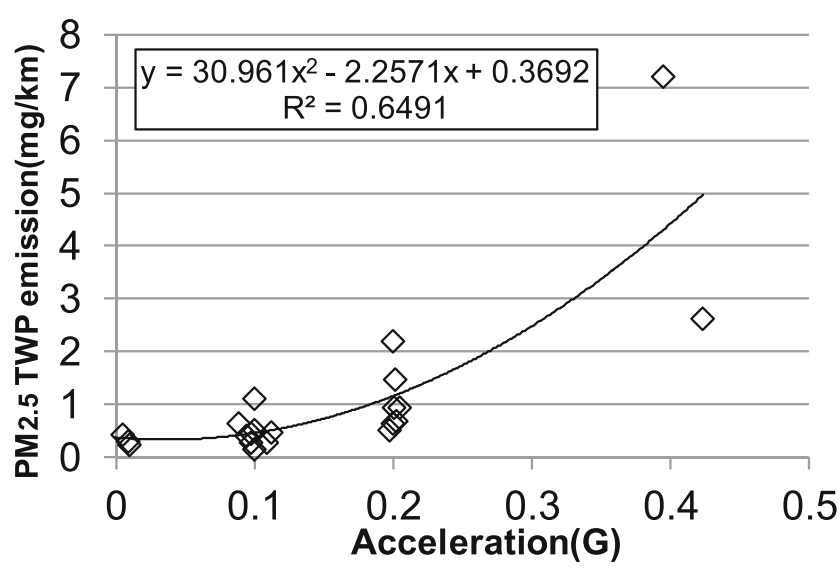

Fig. 5 Relationship between lateral acceleration force and tire-wear particle emission

the amount of tire-wear particles and the tire tread wear mass. Figure 7 shows the relationship between lateral acceleration and tire tread wear. As is shown, the degree of tread wear increased in a quadratic function, similar to the generation of tire-wear particles described above.

We evaluated the generation ratio of tire-wear particles less than 10 and $2.5 \mu \mathrm{m}$ from the measurement results of tire-wear particles and tread wear. Figure 8 shows the ratio of particles less than 10 and $2.5 \mu \mathrm{m}$ to the tread wear under each lateral acceleration condition. As is shown, the generation ratio of the tire-wear particles tended to decrease as the lateral acceleration increased. Even under the highest generation ratio, the ratio of the tire-wear particles to tread wear was about $3.3 \%$ at $\mathrm{PM}_{2.5}$ and $3.7 \%$ at $\mathrm{PM}_{10}$. Based on these results, we concluded that the proportion of tire-wear particles with a size suspended in the air was small, and that most of the tire tread wear dust remained on the road surface.

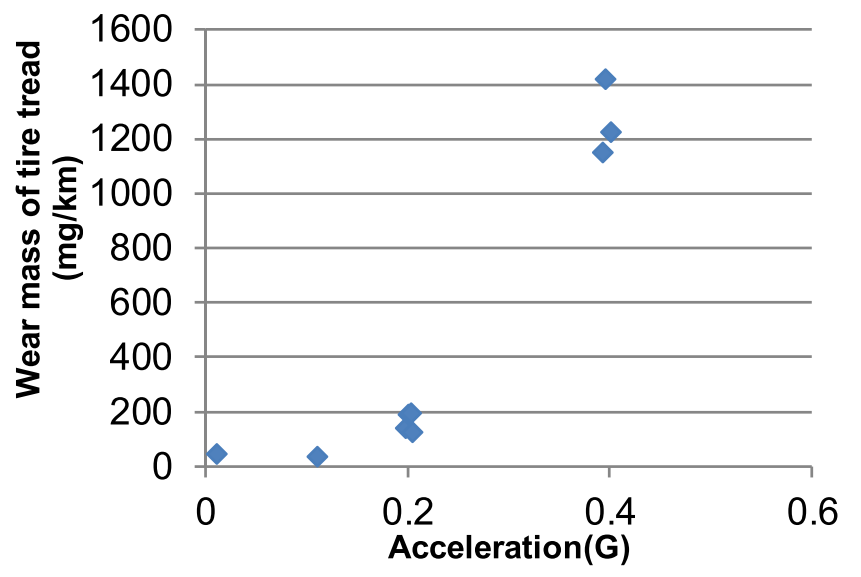

Fig. 7 Relationship between tire wear amount and lateral acceleration

\section{Summary}

A method for measuring tire-wear particles for passenger car tires was studied using a road tire test vehicle.

Tire-wear particles generated in a laboratory test and a road test were collected, and the two samples were observed under an electron microscope. The tire-wear particles obtained from the laboratory test were dramatically different in size and shape compared with those obtained in the road test. Based on this, we concluded that it would be better to evaluate the level of tire-wear particles generated in the road test than in the laboratory test.

A method for generating and collecting tire-wear particles using an on-road test car was developed. The number of tirewear particles generated was not affected by speed change but was greatly affected by a change in the lateral acceleration.

The relationship between the number of tire-wear particles generated and the lateral acceleration could be expressed with quadratic polynomial regression.
Fig. 6 Instantaneous and cumulative emission of tire-wear particles in the JC08 test cycle
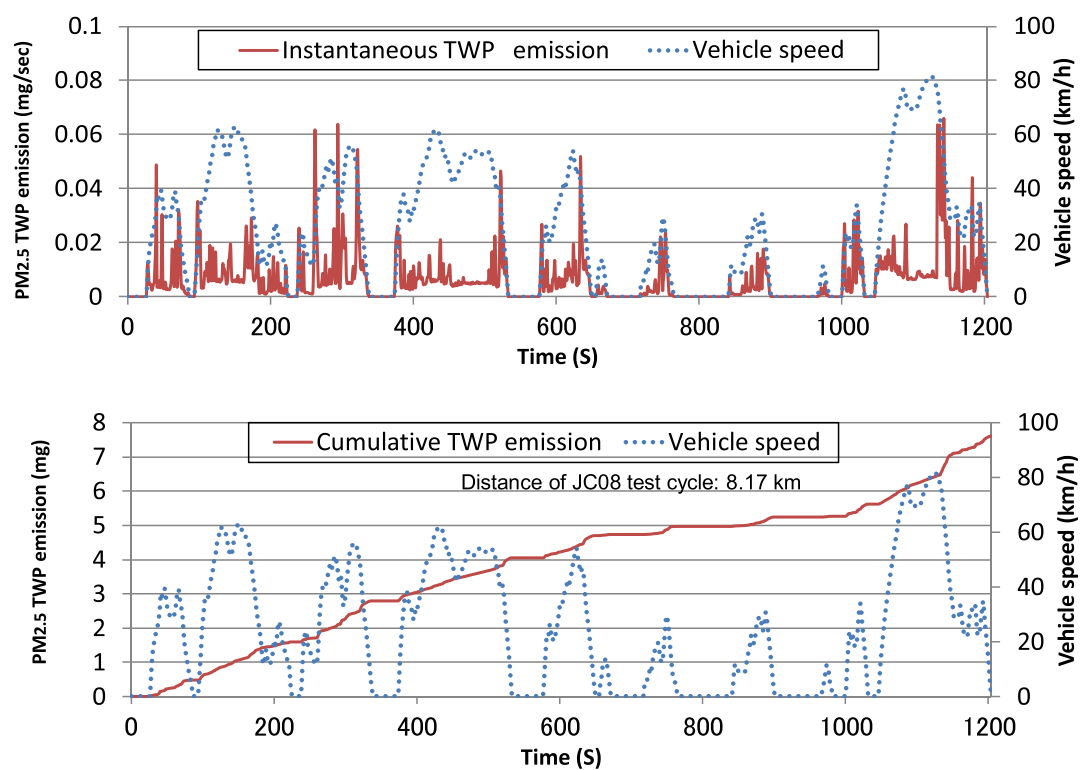


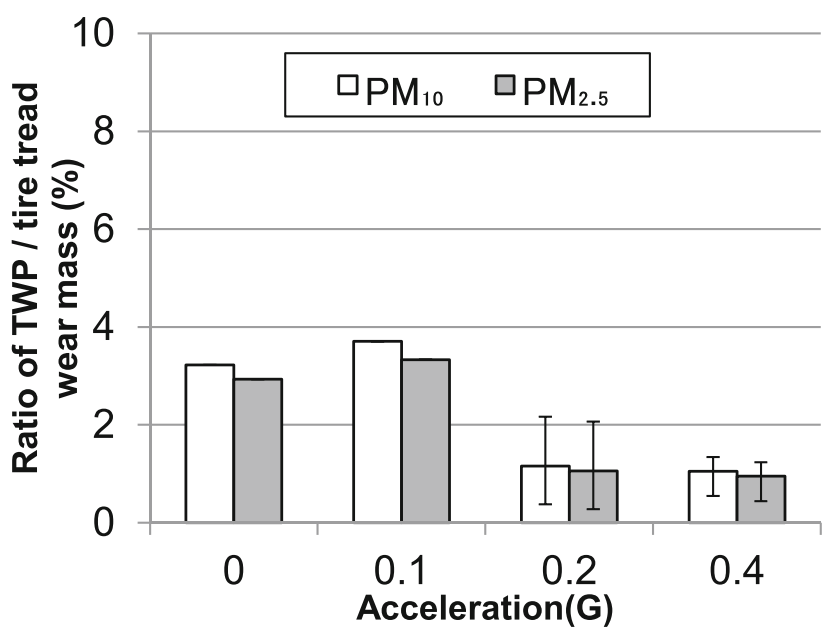

Fig. 8 Ratio of tire-wear particles less than 2.5 and $10 \mu \mathrm{m}$ to tread wear mass. The error bars are the maximum and minimum values

Fitting the regression equation to the speed pattern of the JC08 mode showed that the emission factor of the wear particles of the tire used in the test was $3.7 \mathrm{mg} /$ km-vehicle.

The generation ratio of airborne size particles $\left(\mathrm{PM}_{10}\right.$, $\mathrm{PM}_{2.5}$ ) from worn tire dust was around $3-4 \%$ or less. Therefore, it was predicted that most of the tire dust remained on the road surface as coarse particles and a small amount of the tire dust floated in the atmosphere.

\section{Future Work}

In this study, a measurement test of tire-wear particles based on the change of lateral acceleration force of a test tire was carried out to collect a large amount of TRWP. The emission factors of tire-wear particles were estimated from the relational expression obtained in the investigation. It is possible that the emission factors differed from the actual results of discharge in the vehicle, since the estimation was performed by applying the lateral acceleration to the longitudinal acceleration. A test method based on an actual vehicle was also constructed, and a tire-wear particle measurement test is now in progress.

Open Access This article is licensed under a Creative Commons Attribution 4.0 International License, which permits use, sharing, adaptation, distribution and reproduction in any medium or format, as long as you give appropriate credit to the original author(s) and the source, provide a link to the Creative Commons licence, and indicate if changes were made. The images or other third party material in this article are included in the article's Creative Commons licence, unless indicated otherwise in a credit line to the material. If material is not included in the article's
Creative Commons licence and your intended use is not permitted by statutory regulation or exceeds the permitted use, you will need to obtain permission directly from the copyright holder. To view a copy of this licence, visit http://creativecommons.org/licenses/by/4.0/.

\section{References}

1. Thorpe, A., Harrison, R.M.: Sources and properties of non-exhaust particulate matter from road traffic: A review. Sci. Total Environ. 400, 270-282 (2008)

2. Christopher Frey, H.: Trends in onroad transportation energy and emissions. J. Air Waste Manage. Assoc. 68(6), 514-563 (2018)

3. Terms of reference and rules of procedure for the Informal Working Group on the Particle Measurement Programme, Retrieved August 28, 2018, from https://www.unece.org/fileadmin/DAM/trans/doc/ 2016/wp29grpe/GRPE-73-15-Rev.1.pdf

4. PMP - Particle Measurement Program UNECE Informal Group Non-exhaust traffic related particle emissions, Retrieved August 28, 2018, from https://www.unece.org/fileadmin/DAM/trans/doc/ 2016/wp29grpe/GRPE-73-14.pdf

5. Grigoratos, T., Martini, G.: Brake wear particle emissions: a review. Environ. Sci. Pollut. Res. 22, 2491-2504 (2015)

6. PMP-IWG, Terms of reference and rules of procedure for the Informal Working Group on the Particle Measurement Programme, Retrieved December 4, 2019, from http://www. unece.org/fileadmin/DAM/trans/doc/2019/wp29grpe/GRPE-7914r1e.pdf

7. TRWP Global Sampling Project Summary Report, (2011)

8. Panko, J.M., Hitchcock, K.M., Fuller, G.W., Green, D.: Evaluation of tire wear contribution to PM2.5 in urban environments. Atmosphere. 10(2), 99 (2019)

9. Grigoratos, T., Gustafsson, M., Eriksson, O., Martini, G.: Experimental investigation of tread wear and particle emission from tyres with different treadwear marking. Atmos. Environ. 182, 200-212 (2018)

10. Foitzika, M., Unraua, H., Gauterina, F., Dörnhöferb, J., Kochb, T.: Investigation of ultra fine particulate matter emission of rubber tires. Wear. 394-395, 87-95 (2018)

11. Kreider, M.L., Panko a, J.M., McAtee, B.L., Sweet, L.I., Finley, B.L.: Physical and chemical characterization of tire-related particles: Comparison of particles generated using different methodologies. Sci. Total Environ. 408, 652-659 (2010)

12. Kuhns, H., Etyemezian, V., Landwehr, D., MacDougall, C., Pitchford, M., Green, M.: Testing Re-entrained Aerosol Kinetic Emissions from Roads (TRAKER): a new approach to infer silt loading on roadways. Atmos. Environ. 35, 2815-2825 (2001)

13. Husseina, T., Johanssona, C., Karlssona, H., Hanssona, H.C.: Factors affecting non-tailpipe aerosol particle emissions from paved roads: On-road measurements in Stockholm, Sweden. Atmos. Environ. 42, 688-702 (2008)

14. A. Evans and R. Evans, The composition of a tyre: typical components, the waste \& resources action programme (2006) TYR0009-02.

15. Tonegawa, Y., Sasaki, S.: Investigation of analytical methods for tire wear particles. JARI Res. J. 12, (2012)

Publisher's Note Springer Nature remains neutral with regard to jurisdictional claims in published maps and institutional affiliations. 